\title{
Effects of Beta Cypermethrin on Enzyme Activities of Zebrafish (Brachydanio Rerio)
}

\author{
Jia Jin ${ }^{\mathrm{a}}$, Songlin Zhang ${ }^{b^{*}}$, Pengpeng Wang ${ }^{\mathrm{c}}$ and Min Zhang ${ }^{\mathrm{d}}$ \\ College of Geography and Environmental Science, Northwest Normal University, Lanzhou, P. R. China, \\ 730070
}

a83634283@qq.com, bzhangsonling65@163.com, 'ctawpp@163.com, d344055830@qq.com

*The corresponding author

Keywords: Beta cypermethrin; Zebrafish; Mortality; SOD; POD

\begin{abstract}
In this paper, zebrafish was used as a model organism to study the toxicity of beta cypermethrin with different concentration gradient on the whole zebra fish, and the effects on superoxide dismutase (SOD) and peroxidase (POD) activities of zebra fish brain tissue. As a result, was found among the mortality rate of zebra fish and the concentration or exposure time of beta cypermethrin, and thus showed a dose - effect or time - effect relationship between each other. The correlation coefficient of dose - effect relationship (>0.9) showed that the dose of beta cypermethrin was significantly related to its toxic effect on zebra fish. The $96 \mathrm{~h} \mathrm{LC}_{50}$ of beta cypermethrin was 0.650 $\mathrm{mg} / \mathrm{L}$, and so beta cypermethrin was a highly toxic chemical according to the chemical toxicity classification standard of fish acute toxicity experiment. In addition, a linear negative correlation was found between the damage degree of tissues and the decrease extent of enzyme activities of zebra fish and the concentration and/or extension time of beta cypermethrin. In particular, beta cypermethrin had an inhibitory effect on SOD activity and a suppressing effect after induction on POD activity.
\end{abstract}

\section{Introduction}

Thousands of pesticides were produced and used in the world; more than half were from China. As high as 500, $000 \sim 600,000$ tons of pesticides were used per year in our country, the area of pesticide use was more than 280 million $\mathrm{hm}^{2}$, and about $80 \%$ of which directly entered the environment [1]. The widespread use of pesticide brought the significant benefits to people, and the great negative impact on the environment was consequent at the same time. As an example, people's health was also realistically and potentially damaged by the severe food safety problems caused by the pesticide residue. Through transmission and amplification of the food chain, the pesticide pollution endangered the whole ecosystem, for example, DDT was detected in the body of seal and penguin in Antarctica [2]. A large number of free radicals were produced in the body of aquatic organism because of peroxide stress from environmental pollution [3]. As the antioxidant defense system of organism, the superoxide dismutase (SOD) and peroxidase (POD) could make the appropriate responses to pesticide pollution, so as to reduce their damage to the body.

Beta cypermethrin was not only the efficient isomer of cypermethrin but also the organ chlorine pesticide; it belonged to the parathyroid insecticide, and had a high biological activity. Beta cypermethrin also had stomach and contact poisoning [4], as well as the higher insecticidal efficiency, so it was often used for the pest prevention and treatment of cotton, fruits, vegetables, and trees ${ }^{[5,6]}$.

Zebra fish (Brachydanio radio) had different features, such as small volume, fast breeding, easy to feed and observe, and it was cheap [7] and sensitive to poisons. Besides, the genetic similarity between zebra fish and human was as high as $87 \%$ [8]. So, the test results from zebra fish could also be applied to the human body in most cases. To sum up, zebra fish was often used as the model organism in environmental toxicology research [9-10]. Therefore, the zebra fish was adopted to test the toxicity of 
beta cypermethrin on the whole body and their effects on the SOD and POD activities of brain tissue, so as to provide a scientific basis for their risk assessment and environmental management.

\section{Materials}

Commodity agent Beta cypermethrin (including $4.5 \%$ effective ingredient, EC) was purchased from the Green Pesticide Limited Liability Company (LLC), Shandong province. Zebra fish (Brachydanio radio) was purchased from the Peach Sea Market, Lanzhou, Gansu province, and domesticated in laboratory according to GB/T13267-1991---Determination Methods for Acute Toxicity of Water Quality Materials on Freshwater Fish (Zebra fish). The SOD and POD test kits were bought from the Jiancheng Science and Technology Limited Liability Company, Nanjing, Jiangsu province.

\section{Methods}

Acute Toxicity Experiment. The experimental conditions with Zebra fish were as follows: natural light cycle; the $25 \sim 27{ }^{\circ} \mathrm{C}$ tap water with $24 \mathrm{~h}$ adequate aeration; $\mathrm{pH} 6.5 \sim 7.5$; and the content of dissolved oxygen $\geqslant 5.0 \mathrm{mg} / \mathrm{L}$. The healthy zebra fish should be domesticated for 7 days for the acute toxicity test of beta cypermethrin [11].

The beta cypermethrin solutions of $0.25,0.5,0.75,1.00,1.25,1.50$ and $1.75 \mathrm{mg} / \mathrm{L}$ were made up with the tap water with $24 \mathrm{~h}$ adequate aeration. Three parallels for each concentration group and a blank control group were set at the same time. The 10 healthy and lively zebrafishs with sex ration 1:1, $2.5 \mathrm{~cm}$ length and $0.2 \mathrm{~g}$ weight were chosen and randomly grouped. The experiment was operated in a constant temperature box lasting for $96 \mathrm{~h}$, and the beta cypermethrin solution should be changed every 24 hours. The growth conditions of zebra fish were observed and recorded periodically, and the dyed should be taken out on time. The Zebra fish were not fed $1 \mathrm{~d}$ before and during the experiment.

Enzyme Activity Test. Two zebra fish were taken from each concentration group every $24 \mathrm{~h}$ to dissect their heads for making the crude enzyme liquid. The physiological saline was added to the head at a proportion of $\mathrm{m}: \mathrm{V}=1: 9$, and then grinded the mixture rapidly to get a tissue homogenate of $10 \%$. The supernatants centrifuged at $2500 \mathrm{r} / \mathrm{min}$ for $25 \mathrm{~min}$ were used to determine the enzymes activities.

Enzyme Protein Concentration. The crude enzyme liquids were diluted according to volume ratio $1: 10$, and then the protein concentrations were determined by Coomassie Brilliant Blue method (Bradford) [12].

SOD Activity (The hydroxylamine method [13-15]). The superoxide anion free radicals were produced from the xanthine oxidation by xanthine oxidase, and then oxidized the hydroxylamine to form nitrite, and thus the purple color appeared with the effect of chromogenic agent. The absorbance should be measured at $550 \mathrm{~nm}$ with a visible spectrophotometer. The SOD in the test samples inhibited the superoxide anion free radicals specifically, the concentrations of nitrite were reduced, and the absorbance values of the sample groups were lower than those of the control groups. The SOD activities of measured samples should be calculated as Eq. 1:

$$
\mathrm{SOD}(\mathrm{U} / \mathrm{mgprot})=\frac{\mathrm{OD}-\mathrm{OD}_{1}}{\mathrm{OD}} \div 50 \% \times \frac{\mathrm{V}}{\mathrm{V}_{1}} \div \mathrm{C}(\mathrm{mgprot} / \mathrm{m} \mathrm{l})
$$

Where OD was the absorbance value of the control group, $\mathrm{OD}_{1}$ was the absorbance value of the sample group, $\mathrm{V}$ was the total volume of reacted liquid, $\mathrm{V}_{1}$ was the volume of the measured liquid, and $\mathrm{C}$ was the concentration of the protein.

POD Activity. The POD, similar to SOD, was an oxidation-reduction enzyme of organism to remove the oxygen free radicals [16]. The guaiacum was used as substrate by POD to catalyze $\mathrm{H}_{2} \mathrm{O}_{2}$ 
oxidase into a dark brown product [17-18]. This product was used to determine the POD activity because of its maximum absorbance at $470 \mathrm{~nm}$.

The mixture of $3.00 \mathrm{~mL}$ crude enzyme fluid, $5.00 \mathrm{~mL}$ distilled water and $1.00 \mathrm{~mL} 0.3 \%$ guaiacum solution were shaken thoroughly, the $1.00 \mathrm{~mL} 0.50 \mathrm{moll} / \mathrm{L} \mathrm{H}_{2} \mathrm{O}_{2}$ solution was added and blend well, and reacted accurately at $25{ }^{\circ} \mathrm{C}$ for $25 \mathrm{~min}$, then the absorbance's were determined at $470 \mathrm{~nm}$. The control group was treated similarly with $8.00 \mathrm{~mL}$ distilled water. The POD activity should be calculated as Eq. 2:

$$
P O D(\mu g / m g \cdot \min )=\frac{m}{V \times c \times t}
$$

Where $\mathrm{m}$ was the mass $(\mathrm{mg})$ of guaiacum oxidized in $25 \mathrm{~min}$, V was the volume (ml) of enzyme fluid, $\mathrm{t}$ was the reaction time $(\mathrm{min})$, and $\mathrm{c}$ was the concentration $(\mathrm{mg} / \mathrm{ml})$ of enzyme protein.

\section{Data Analysis}

Results were presented as mean \pm standard deviation. The data were analyzed with SPSS version 16.0, and the variance of one-way ANOVA was in the confidence level $P<0.05$ [19].

\section{Results and Discussions}

The Acute Toxicity of Beta Cypermethrin on Zebra fish. The results of linear regression analysis in Probity of SPSS 16.0 for the acute toxicity of beta cypermethrin on zebra fish were shown in table 1, and the $\mathrm{LC}_{50}$ values and their $95 \%$ confidence intervals were shown in table 2.

Table 1 Acute toxicity effects of beta cypermethrin on zebra fish

\begin{tabular}{cccccc}
\hline \multirow{2}{*}{ Concentration $[\mathrm{mg} / \mathrm{L}]$} & $24 \mathrm{~h}$ & $48 \mathrm{~h}$ & $72 \mathrm{~h}$ & $96 \mathrm{~h}$ & $\begin{array}{c}\text { Correlation Coefficient of } \\
\text { Time - Effect }\end{array}$ \\
\hline 0.25 & 0 & 0 & 0 & 20 & 0.7746 \\
0.5 & 0 & 10 & 10 & 40 & 0.8944 \\
0.75 & 10 & 20 & 30 & 60 & 0.9562 \\
1.00 & 10 & 40 & 50 & 80 & 0.9839 \\
1.25 & 30 & 50 & 70 & 90 & 1.0000 \\
1.5 & 40 & 70 & 80 & 100 & 0.9812 \\
1.75 & 60 & 90 & 100 & 100 & 0.8866 \\
Correlation Coefficient of & 0.9526 & 0.9922 & 0.9965 & 0.9678 & \\
Dose - Effect & & & & & \\
\hline
\end{tabular}

The results showed that a linear positive correlations of dose - effect and time - effect was found between for the concentrations of beta cypermethrin and the acute toxicities of beta cypermethrin on zebra fish; That is to say, with the increase of concentration and infecting time of beta cypermethrin, the mortalities of zebra fish were linearly increasing, too; All the correlation coefficients of dose effect (>0.9) showed that it was a significant positive correlation (Table 1, Table 2 and Fig. 1). The 96h $\mathrm{LC}_{50}$ value of beta cypermethrin was $0.650 \mathrm{mg} / \mathrm{L}$ (Table 2), and thus beta cypermethrin was a highly toxic chemical $(<1 \mathrm{mg} / \mathrm{L})$ according to the chemical toxicity classification standard of fish acute toxicity experiment. 
Table 2 Acute toxicity effects of beta cypermethrin on zebra fish

\begin{tabular}{ccc}
\hline Time $[\mathrm{h}]$ & $\mathrm{LC}_{50}[\mathrm{mg} / \mathrm{L}]$ & $95 \%$ Confidence Interval $[\mathrm{mg} / \mathrm{L}]$ \\
\hline 24 & 1.624 & $1.345 \sim 2.689$ \\
48 & 1.114 & $0.912 \sim 1.378$ \\
72 & 0.950 & $0.777 \sim 1.123$ \\
96 & 0.650 & $0.426 \sim 0.749$ \\
\hline
\end{tabular}

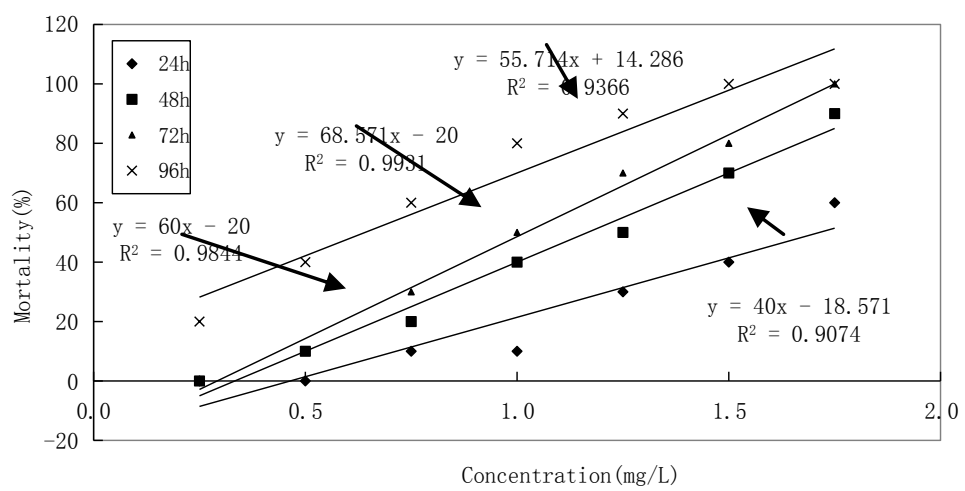

Figure 1. Dose / time - effect between mortality of zebra fish and concentration of beta cypermethrin

Effects of Beta Cypermethrin on the SOD Activity of Zebra fish. The effects of beta cypermethrin with a different concentration gradient on the SOD activity of zebra fish brain tissue were shown in Table 3 and Fig. 2. Compared with the control group and the SOD activities of the experimental groups were inhibited by the influence of beta cypermethrin. With the concentration and the exposure time of beta cypermethrin increasing, all the SOD activities of zebra fish brain tissues had a significant decline in straight line, and the correlation coefficients were all below 0.9, that was to say, a significant linear negative correlations of dose - effect and time - effect existed between the beta cypermethrin and the SOD activity of zebra fish brain tissue.

Table 3 Acute effects of beta cypermethrin on SOD activity of zebra fish brain tissue

\begin{tabular}{|c|c|c|c|c|c|c|c|c|}
\hline \multirow{2}{*}{ Time $[\mathrm{h}] \quad$ Enzyme Activity } & \multicolumn{7}{|c|}{ Beta Cypermethrin $[\mathrm{mg} / \mathrm{L}]$} & \multirow{2}{*}{$\begin{array}{c}\text { Correlation } \\
\text { Coefficient } \\
\text { of Dose - Effect }\end{array}$} \\
\hline & 0.25 & 0.5 & 0.75 & 1.00 & 1.25 & 1.5 & 1.75 & \\
\hline 24 & 172.14 & 170.18 & 168.34 & 166.49 & 163.42 & 160.96 & 159.12 & -0.9969 \\
\hline 48 & 167.11 & 164.03 & 162.81 & 160.35 & 157.89 & 156.05 & 15 & -0.9970 \\
\hline 72 & 160.35 & 159.12 & 156.66 & 154.82 & 152.36 & 150.52 & 149.29 & -0.9965 \\
\hline 96 & 158.51 & 157.28 & 154.82 & 152.98 & 151.75 & 149.49 & 148.06 & -0.9973 \\
\hline $\begin{array}{c}\text { Correlation Coefficient of } \\
\text { Time - Effect }\end{array}$ & -0.9797 & -0.9756 & -0.9795 & -0.9768 & -0.9585 & -0.9696 & -0.9731 & \\
\hline
\end{tabular}




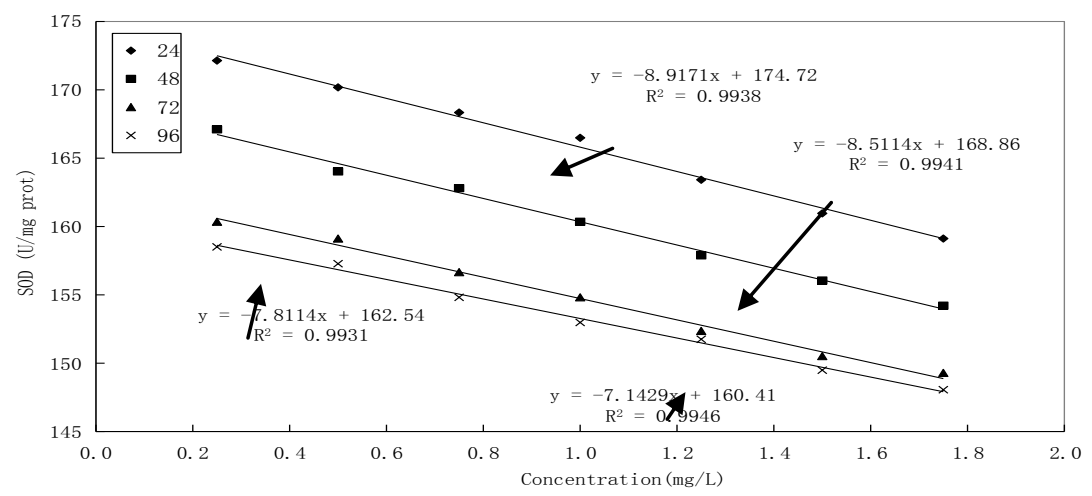

Figure 2. Effects of beta cypermethrin on the SOD activity of zebra fish brain tissue

Effects of Beta Cypermethrin on the POD Activity of Zebra fish. The effects of beta cypermethrin at a different concentration gradient on the POD activity of zebra fish brain tissue were shown in Table 4 and Fig. 3. Compared with the blank group, the POD activities of the experimental groups showed suppressing effects after inductions by the influence of beta cypermethrin. Specifically, with the exposure time increasing, the POD activities of zebra fish brain tissue at the same concentration showed a significant decline in straight line, and the correlation coefficients were all below 0.9, which illustrated that there was a significant linear negative correlation of time - effect between the exposure time of beta cypermethrin and the POD activity of zebra fish brain tissue. However, at the same time, with the concentrations of beta cypermethrin increasing, the POD activities of zebra fish brain tissues were first up and then down, the linear correlation coefficients $(>-0.5)$ showed a lite significant linear correlation in straight, the most correlation coefficients $(>0.9)$ showed a significant relationship of unary cubic polynomial. Beta cypermethrin with the concentration greater than $0.75 \mathrm{mg} / \mathrm{L}$ had a suppressing effect on the POD activity, and the enzyme activity changes were more obvious. Beta cypermethrin at low concentration activated the antioxidant enzyme POD in the body of zebra fish; with the growth of concentration and exposure time, the pollutants produced a large number of free radicals beyond the resistive ability of zebra fish, leading to cell damage and lower POD activity.

Table 4 Acute effects of beta cypermethrin on POD activity of zebra fish brain tissue

\begin{tabular}{|c|c|c|c|c|c|c|c|c|}
\hline \multirow{2}{*}{$\begin{array}{l}\text { Enzyme Activity } \\
{[\mu \mathrm{g} / \mathrm{mg} \text { port }]} \\
\text { Time }[\mathrm{h}]\end{array}$} & \multicolumn{7}{|c|}{ Beta Cypermethrin $[\mathrm{mg} / \mathrm{L}]$} & \multirow{2}{*}{$\begin{array}{c}\text { Correlation Coefficient of } \\
\text { Dose - Effect }\end{array}$} \\
\hline & 0.25 & 0.5 & 0.75 & 1.00 & 1.25 & 1.5 & 1.75 & \\
\hline 24 & 8.2 & 9.97 & 11.76 & 11.48 & 10.81 & 9.07 & 8.75 & -0.0610 \\
\hline 48 & 6.61 & 8.04 & 9.89 & 9.7 & 6.37 & 6.22 & 5.94 & -0.4206 \\
\hline 72 & 4.79 & 6.23 & 6.93 & 6.69 & 5.74 & 5.5 & 5.15 & -0.1529 \\
\hline 96 & 3.96 & 5.17 & 5.94 & 5.82 & 5.11 & 4.17 & 3.59 & -0.3286 \\
\hline $\begin{array}{c}\text { Correlation } \\
\text { Coefficient } \\
\text { of Time - Effect }\end{array}$ & -0.9898 & -0.9921 & -0.9845 & -0.9812 & -0.8849 & -0.9622 & -0.9718 & \\
\hline
\end{tabular}




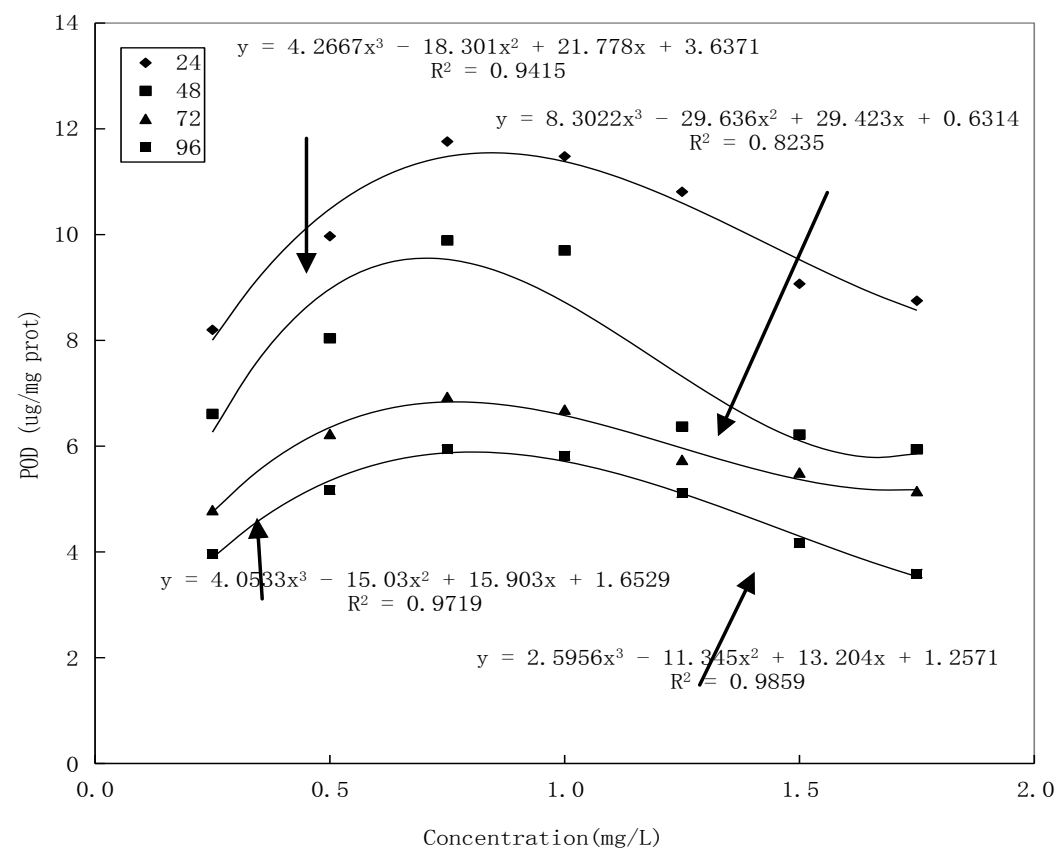

Figure 3. Effects of beta cypermethrin on the POD activity of zebra fish brain tissue

\section{Conclusions}

Using zebra fish as a test organism, this paper researched the acute toxicity of beta cypermethrin on the whole zebra fish and its effects on the activity of SOD and POD of zebra fish. The results showed that:

(1) A significant positive correlation of dose - effect existed between the mortality of the zebra fish and the concentration of beta cypermethrin, and a higher positive correlation of time-effect existed between the mortality of the zebra fish and the exposure time of beta cypermethrin.

(2) The $96 \mathrm{~h} \mathrm{LC}_{50}$ value of beta cypermethrin on zebra fish was $0.650 \mathrm{mg} / \mathrm{L}$, so beta cypermethrin was a highly toxic chemical.

(3) A significant linear negative relationships in straight of dose - effect and time - effect existed between the concentration and exposure time of beta cypermethrin and the SOD activity of zebra fish brain tissue.

(4) At the same concentration, there was a significant linear negative correlation in straight of time effect between the concentration of beta cypermethrin and the POD activity of zebra fish brain tissue; Meanwhile, at the same exposure time, the relationship between the concentration of beta cypermethrin and the POD activity in zebra fish brain tissue was a unary cubic polynomial of inhibition after induction with a significant correlation coefficient.

\section{Acknowledgements}

The authors are very grateful for the financial support from the National Natural Science Fund of China (51068025), the Natural Science Fund of Gansu Province in China (1308RJZA302), and the Open Research Fund of Oil and Gas Resources Key Laboratory of Gansu Province in China (SZDKFJJ20150606).

\section{References}

[1] S.N. Wang, Y.C. Li: Modern Preventive Medicine, Vol. 34 (2007) No.20, p.3853 (In Chinese)

[2] Z.H. Song, Y.Y. Zhang: Journal of Hydro ecology, Vol. 5 (2007) No.4, p.89 (In Chinese) 
[3] M. Jiao, X. Sun, B. Li and Z. Wu: Act Agriculture Jiangxi, (2007) No.3, p.110 (In Chinese)

[4] X.P. Huang, Ping. J and B.R. Gang: Sichuan Journal of Zoology, (2013) No.4, p.555 (In Chinese)

[5] Y.D. Wang, C.X. Li and X.M. Xia: Journal of Anhui Agricultural Science, (2007) No.5, p.93 (In Chinese)

[6] P. Ma, L.J. Qin and Y.R. Zhang: Act Scientiae Circumstantiate, Vol. 32 (2012) No.3, p.757 (In Chinese)

[7] Y. Huang, J. Cain and B. Wang: Journal of Anhui Agricultural Sciences, Vol. 43 (2015) No.25, p.138 (In Chinese)

[8] L.P. Qiu, L.M. Fan and Q. Liu: Journal of Anhui Agricultural Sciences, Vol. 43 (2015) No.19, p.91 (In Chinese)

[9] C.Y. Usenko, S.L. Harper and R.L. Tanguay: Carbon, Vol. 45 (2007) No.9, p.1891

[10]B. Fraysse, R. Mons and J Garric: Ecotoxicology \& Environmental Safety, Vol. 63 (2006) No.2, p. 253

[11] Y.D. Zhao, D.M. Xu, Q.H. Fan and X.J. Liu: Jiangsu Journal of Agricultural Sciences, Vol. 24 (2008) No.6, p.989 (In Chinese)

[12] X.Y. Liu, Q. Hao and M.C. Wu: Journal of Food Science, Vol. 27 (2006) No.12, p.71 (In Chinese)

[13] S.Y. Wang, W. Huang and J. Bai: Journal of Medical Research, (2016) No.4, p.85 (In Chinese)

[14] J.Y.Zheng, H. Wu and W. Tang: Journal of Wenzhou Medical College, Vol. $46-48$ (2016) No.7, p.469 (In Chinese)

[15] Y.M. Zhang, H.T. Li and C.M. Wang: Practical Journal of Dermatology, Vol. 9 (2016) No.2, p.84 (In Chinese)

[16]Q.W. Wang: Single and Joint Toxicity Effects of Heavy Metals, TPT and PCP on Zebrafish (Brachydanio Rerio)(MS., Qingdao University of Science \& Technology, China 2011)

[17] Q.F. Wen, R.T. Liu and G. Wang: Journal of Plant Genetic Resources, Vol. 4 (2003) No.4, p.318 (In Chinese)

[18] X.B. Peng: Journal of Shanxi Agricultural Science, Vol. 21 (2015) No.7, p.28 (In Chinese)

[19] S.Q. Tao, F.A. Wu: Journal of Guangxi Sericulture, (2005) No.4, p.24 (In Chinese) 